Journal of Cellular Biochemistry

WILEY

\title{
Berberine induces autophagic cell death and mitochondrial apoptosis in liver cancer cells: the cellular mechanism
}

\begin{tabular}{|c|c|}
\hline Journal: & Journal of Cellular Biochemistry \\
\hline Manuscript ID: & JCB-09-0456.R2 \\
\hline Wiley - Manuscript type: & Research Article \\
\hline $\begin{array}{r}\text { Date Submitted by the } \\
\text { Author: }\end{array}$ & 19-May-2010 \\
\hline Complete List of Authors: & $\begin{array}{l}\text { Wang, Ning; The University of Hong Kong, Schoo of Chinese } \\
\text { Medicine } \\
\text { Feng, Yibin; The University of Hong Kong, School of Chinese } \\
\text { Medicine } \\
\text { Zhu, Meifen; The University of Hong Kong, School of Chinese } \\
\text { Medicine } \\
\text { Tsang, Chi-Man; The University of Hong Kong, Anatomy } \\
\text { Man, Kwan; The University of Hong Kong, Surgery } \\
\text { Tong, Yao; The University of Hong Kong, Schoo of Chinese Medicine } \\
\text { Tsao, Sai-Wah; The University of Hong Kong, Anatomy }\end{array}$ \\
\hline Keywords: & Berberine, Autophagy, Apoptosis, Bcl-2/Beclin-1, mTOR \\
\hline
\end{tabular}

\section{s scholarONE" \\ Manuscript Central}


Berberine induces autophagic cell death and mitochondrial apoptosis in liver cancer cells: the cellular mechanism

Ning Wang ${ }^{1}$, Yibin Feng ${ }^{1}$, Meifen Zhu ${ }^{1}$, Chi-Man Tsang ${ }^{2}$, Kwan Man ${ }^{3}$, Yao Tong ${ }^{1}$, Sai-Wah Tsao $^{2 *}$

1 School of Chinese Medicine, The University of Hong Kong, 10 Sassoon Road, Pokfulam, Hong Kong, RP of China

2 Department of Anatomy, The University of Hong Kong, 21 Sassoon Road, Pokfulam, Hong Kong, RP of China

3 Department of Surgery, The University of Hong Kong, 21 Sassoon Road, Pokfulam, Hong Kong, RP of China

*Corresponding authors: yfeng@hku.hk, gswtsao@hkucc.hku.hk

Running Title: Berberine induces autophagy and apoptosis in cancer cells 


\begin{abstract}
Extensive studies have revealed prominent anti-tumor actions of berberine, a small molecule derived from Coptidis Rhizoma (Huanglian in Chinese) and many other plants. To clarify the berberine induced cell death and underlying mechanisms in cancer cells, we examined autophagy and apoptosis in human hepatic carcinoma cells HepG2 and MHCC97-L. In the present study, the results showed that berberine can both induce autophagy and apoptosis in hepatocellular carcinoma cells. Cell viability of berberine in human hepatic carcinoma cells increased due in the presence of the cell death inhibitor, 3-Methyladenine or by interfering with the essential autophagy gene Atg5. Mechanistic studies showed that berberine may activate mitochondrial apoptosis in HepG2 and MHCC97-L cells via increasing Bax expression, permeability transition pore formation and cytochrome $\mathrm{C}$ release to the cytosol, and subsequent activation of the caspase- 3 and caspase- 9 execution pathway. Berberine may also induce autophagic cell death in HepG2 and MHCC97-L cells via activation of Beclin-1, but inhibition of the mTOR signaling pathway by suppressing the activity of Akt and up-regulating P38 MAPK signaling. This is the first time that contribution of the activation of Beclin-1 and inhibition of mTOR in the mechanism of berberine-induced autophagic cell death has been described. These results further demonstrate the potential of berberine as a therapeutic agent in the emerging list for cancer therapies with novel mechanisms.
\end{abstract}

Key word: Berberine; autophagy; apoptosis; Bcl-2/Beclin-1; mTOR 


\section{Introduction}

Hepatocellular carcinoma (HCC), amounting for $80 \%$ to $90 \%$ of liver cancer, has become one of the most common and prevalent human malignancies in the world [Budhu et al., 2008]. However, effective therapy of this malignancy remains rare and poor. One of the important approaches for liver cancer treatment is chemotherapy, in which the main mechanism of chemotherapeutic agents is to cause cancer cell death. Several types of cell death have been classified and defined by the Nomenclature Committee on Cell Death (NCCD), including apoptotic and autophagic cell death. These two types of cell death, also known as Type I and Type II Programmed Cell Death (PCD) respectively, differ in morphological features and signal transduction but share the same result on cell death [Kroemer et al., 2009]. Apoptosis is considered as a conventional type of cell death whereas autophagic cell death is simply defined as cell death with autophagy, which process is also thought to be one of the mechanisms for cell survival [Galluzz et al., 2008]. Recently, extensive studies reported apoptosis and autopahgy were both involved in chemotherapeutic agents-induced cancer cell death [Cheng et al., 2009; Kim et al., 2009], suggesting that apoptosis and autophagy be important for illustrating the underlying mechanism for novel therapeutic agents.

Berberine is a natural product derived from many kinds of herbs, like Coptidis Rhizoma (Huanglian in Chinese), Hydrastis canadensis, Berberis aquifolium, Berberis aristata and Berberis vulgaris (barberry). Many studies reported the in vitro and vivo anti-cancer effect of 
Huanglian and berberine via different mechanisms [Tang et al., 2009]. Berberine may suppress cancer cells via regulating the cell cycle [Serafim et al., 2008], inhibiting the ATP generation [Pereira, 2007], or inducing cancer cell apoptosis [Pandey et al., 2008]. It was also reported that berberine could suppress cancer invasion and metastasis via regulating the HIF-1 $\alpha$ activity in SC-M1 cells [Lin et al., 2004]. Recently, we found that anti-invasion of berberine may inhibit RhoA signaling pathway at low dose, while apoptosis are induced by berberine via G2 arrest at high dose due to berberine distribution in cell nuclear and cytoplasm in dose dependent manner [Tsang et al., 2009]. These illustrate the potential of berberine for cancer therapy. Previous study reported a synergistic induction of autophagic cell death by radiation and berberine in lung cancer [Peng, et al., 2008], but there's no study focusing on the induction of autophagy by single treatment of berberine. Moreover, no study reveals the contribution of different types of cell death on anticancer effect of berberine and their underlying signaling transduction.

In this study, we reported for the first time that berberine induces both autophagic cell death and mitochondrial apoptosis in human hepatic carcinoma cells, HepG2 and MHCC97-L cells. Berberine showed potent cytotoxicity to various cancer cell lines including HepG2, MHCC97-L, HONE1, Hela and HK1. Berberine can induce mitochondria apoptosis in HepG2 and MHCC97-L cells, shown as a decrease of mitochondria membrane potential and an increase of Bax expression as well as activation of caspase-3 and caspase-9. Berberine can also induce autophagy via activating Beclin-1 and inhibiting mTOR signal pathway in the same cancer cell lines. Inhibition of berberine on mTOR activity may result from both the 
activation of P38 MAPK and suppression of Akt signaling. Inhibition of autophagy by 3-methyladenine (3-MA) treatment or by silencing the autophagy protein 5 (Atg5) gene attenuates cell death induced by berberine, indicating that berberine-induced autophagy contributes to its anticancer effect. By integrating the underlying mechanism of cell death, our finding suggests that berberine, which initiates both apoptotic and autophagic cell death (Type I and Type II cell death), can be added to the list of emerging agents with potential for cancer therapy.

\section{Materials and Methods}

\section{Chemical, plasmid and Antibodies}

Berberine hydrochloride, the autophagy-apoptosis inhibitor 3-methyladenine (3-MA) and autophagosome-lysosome fusion inhibitor bafilomycin A1 were purchased from Sigmaaldrich (USA). The pcDNA3 plasmid encoding human LC3 was kindly gifted by Professor Yoshimori. Anti- Bcl-2, anti-Bax, anti-caspase-3, anti-caspase-9, anti-Beclin-1, anti- $\beta$-actin, anti-phosphorylated mTOR, anti-mTOR, anti-phosphorylated AKT, anti-AKT and anti-COX-IV were purchased from Abcam (UK). Anti-LC3B was purchased from Novus Biologicals (USA). Anti-P38 MAPK, anti-phosphorylated P38 MAPK (Thr180/Tyr182) and anti-Atg5 were purchased from Cell Signaling Technology (USA).

\section{Cell line and Cell culture}

Human hepatocarcinoma cell line HepG2, human nasopharyngeal carcinoma cell line HONE1 
and HK1 were purchased from ATCC (USA). Human liver cancer cell line with high metastatic property MHCC97-L was gifted from Professor Tang and had been used in our previous study [Lee et al., 2005]. Cells were maintained in Dulbecco's Modified Eagle medium with high glucose and incubated in a humidified atmosphere containing $5 \% \mathrm{CO}_{2}$ at $37{ }^{\circ} \mathrm{C}$.

\section{Cell viability assay}

MTT assay was introduced to detect the cytotoxicity of berberine in different cancer cells. In brief, cells were seeded in 96-well plate with DMEM medium (High glucose, supplemented with $10 \%$ FBS) with density of 10,000 cells/well. A series of concentrations of berberine were added for $48 \mathrm{hr}$ incubation. All experiments were conducted parallel with controls $(0.1$ \% DMSO). $15 \mu$ of 3-(4,5-Dimethylthiazol-2-yl)-2,5-diphenyltetrazolium bromide (MTT, 5 $\mathrm{mg} / \mathrm{ml}$, Sigma, USA) were added to each well at the end of treatment and incubated at $37^{\circ} \mathrm{C}$ for $4 \mathrm{hr}$. Then medium was removed and $200 \mu \mathrm{l}$ DMSO was added to each well. The absorbance of formazan formed was measured at $595 \mathrm{~nm}$ by Multiskan MS microplate reader (Labsystems, Finland).

\section{Monodansylcadaverine \& Acridine Orange staining}

Cells were seeded on cover slips and exposed to different concentration of berberine (50, 100 or $200 \mu \mathrm{M}$ in HepG2 cells and 100, 200 or $400 \mu \mathrm{M}$ in MHCC97-L cells respectively) for $6 \mathrm{hr}$. For monodansylcadaverine (MDC) staining, cells were stained by $0.05 \mathrm{mM} \mathrm{MDC}$ in PBS at $37{ }^{\circ} \mathrm{C}$ for 10 minutes [Munafó \& Colombo, 2001]. After incubation, cells were washed with 
PBS for four times and the cover slips were placed onto slides and visualized under fluorescent microscope (Carl Zeiss, USA). For Acridine Orange (AO) staining, cells were stained by $1 \mu \mathrm{g} / \mathrm{mL}$ AO in PBS at $37^{\circ} \mathrm{C}$ for 15 minutes [Yang et al., 2008] followed by wash. Then the cover slips were placed onto slides and visualized under fluorescent microscope (Carl Ziess, USA, 63×, CCD camera).

\section{Quantification of GFP-LC3 puncta}

HepG2 cells were transfected with pcDNA3 plasmid encoding GFP-LC3 using lipofectamine 2000 (Invitrogen, USA) in serum- and antibiotic-free medium for $6 \mathrm{hr}$ followed by $72 \mathrm{hr}$ incubation in growth medium. Then cells were selected with $1 \mathrm{mg} / \mathrm{mL} \mathrm{G} 418$ (Gibico, USA) to establish a cell line stably expressing GFP-LC3 fusion protein. After that, cells were seeded into $35-\mathrm{mm}$ confocal dishes and treated with 50,100 or $200 \mu \mathrm{M}$ of berberine for $6 \mathrm{~h}$. The accumulation of GFP-LC3 was examined by fluorescence microscopy (Carl Ziess, USA, 63×, CCD camera). Autophagy was quantified by counting the percentage of cells showing accumulation of GFP-LC3 in dots. 100 cells per preparation in three independent experiments were calculated. Cells represent several intense punctuate GFP-LC3 aggreagates were classified as autophagic [Shen et al., 2010].

\section{Annexin V/PI Double Staining}

HepG2 and MHCC97-L cells with treatment were collected using micro-scrapper (Corning, USA) and then centrifuged. To detect apoptosis in HepG2 and MHCC97-L cells after exposure to berberine, Annexin V/PI double staining kit (Sigma aldrich, USA) was introduced 
to quantify cell amount in different stages of cell death [Vermes, et al., 1995]. Briefly, cells were re-suspended in $1 \mathrm{~mL}$ of binding buffer containing $100 \mathrm{mM}$ HEPES/NaOH, $1.4 \mathrm{mM}$ $\mathrm{NaCl}, 25 \mathrm{mM} \mathrm{CaCl}$, $\mathrm{pH}$ 7.5. Then $5 \mu \mathrm{l}$ of FITC-conjugated Annexin $\mathrm{V}(50 \mu \mathrm{g} / \mathrm{mL})$ and $10 \mu \mathrm{l}$ of propidium iodide $(100 \mu \mathrm{g} / \mathrm{mL})$ were added and incubated in dark for exactly 10 minutes at room temperature and detected by flow cytometer (Epics XL, Beckman Coulter, USA).

\section{Detection of mitochondria membrane potential (MMP)}

The mitochondrial membrane potential probe, Rhodamine-123 (Rh-123) is used to qualitatively and quantitatively determine the decrease of MMP in HepG2 and MHCC97-L cells treated with serious doses of berberine. For qualitative analysis, HepG2 and MHCC97-L cells were seeded into $30 \mathrm{~mm}$ confocal culture dishes with $40 \%$ confluence. Cells were treated with or without berberine $(50,100$ or $200 \mu \mathrm{M}$ in HepG2 cells and 100, 200 or $400 \mu \mathrm{M}$ in MHCC97-L cells respectively) for $12 \mathrm{hr}$. After treatment, cells were washed with PBS and were stained with $1 \mu \mathrm{mol} / \mathrm{L}$ Rh-123 (Sigma, USA) for 25 minutes at room temperature in dark. Then cells were rinsed and visualized under fluorescent microscope (Carl Ziess, USA, 63×, CCD camera). For quantitative analysis of MMP in berberine treated cells, HepG2 or MHCC97-L cells were cultured in a 96-well black-botomed plate and treated with series concentrations of berberine for $12 \mathrm{hr}$. Cells were washed once with PBS and then incubated with Rh-123 $(1 \mu \mathrm{mol} / \mathrm{L})$ in PBS for 25 minutes. The fluorescence intensity in each well was then measured using a fluorescent microplate spectrometer (LS55, PerkinElmer) with excitation and emission wavelengths at 488 and $530 \mathrm{~nm}$, respectively. 


\section{Measurement of Cytochrome C release}

Cells with or without treatment of berberine was harvested using a micro-scrapper (Corning, USA) and then cytoplasmic protein was extracted by NP-40 lysis buffer (Invitrogen, USA) supplemented with proteinase inhibitor (1\% PMSF, $0.5 \%$ apotinin and $0.5 \%$ leupitine) on ice for 5 minutes followed by centrifugation at $14,000 \mathrm{rpm}$ at $4^{\circ} \mathrm{C}$ for 10 minutes. Supernatant was collected and protein concentration was determined. The release of cytochrome C (Cyto C) was monitored by immunobloting and COX-IV was used to monitor the cleavage of mitochondria fraction.

\section{Immunobloting}

cells with treatment were harvested using a micro-scrapper (Corning, USA) and then lysed with RIPA buffer supplemented with proteinase inhibitor (1\% PMSF, $0.5 \%$ apotinin and $0.5 \%$ leupitine $)$ and phosphatase inhibitor $\left(1 \mathrm{mM} \mathrm{Na}_{3} \mathrm{VO}_{4}\right.$ and $\left.1 \mathrm{mM} \mathrm{NaF}\right)$ on ice for 30 minutes and then centrifuged at $14,000 \mathrm{rpm}$ at $4^{\circ} \mathrm{C}$ for 25 minutes. The supernatant was transferred to a new tube and protein concentration was determined using BSA as a standard. Equal amounts of protein were resolved by SDS-PAGE and transferred onto a polyvinylidene fluoride membrane (PVDF, Biorad). Then the membrane was blocked with 5\% BSA in buffer containing Tris $(10 \mathrm{mmol} / \mathrm{L}, \mathrm{pH} 7.4), \mathrm{NaCl}(150 \mathrm{mmol} / \mathrm{L})$ and Tween $20(1 \%)$ overnight at $4^{\circ} \mathrm{C}$. The membrane was then incubated with primary antibodies at $4^{\circ} \mathrm{C}$ overnight followed by incubation with appropriate secondary antibody (Abcam, UK) at room temperature for 2 hours. The immunoreactivites were detected using ECL advanced kit (GE Healthcare, UK) and visualized using a chemiluminenescence imaging system (Biorad, USA). 


\section{RNA interference}

HepG2 cells stably transfected with plasmid encoding GFP-LC3 were cultured in 35-mm confocal dishes for overnight. Then cells were transfected with siRNA against human ATG5 (Santa Cruz, $1.25 \mu \mathrm{g} / \mathrm{mL}$ ) using transfection reagent Lipofectamine 2000 (Invitrogen, USA) in serum- and antibiotic- free medium for $6 \mathrm{hr}$ and then cultured in normal growth medium for $72 \mathrm{hr}$. Cells were then treated with $100 \mu \mathrm{M}$ berberine for $6 \mathrm{hr}$ and then visualized under fluorescent microscope (Carl Ziess, USA, 63×, CCD camera).

\section{Statistical analysis}

Results were analyzed using student T-test and expressed as mean $\pm \mathrm{SD}$.

\section{Results}

\section{Berberine induce liver cancer cell death in vitro}

Berberine exhibits significant induction on the death of carcinoma cell lines including hepatocellular carcinoma cell HepG2, MHCC97-L, human cervical epithelioid carcinoma cell Hela, nasopharyngeal carcinoma cell HONE1 and HK1 according to MTT assay. The IC50 of berberine in different cancer cells varies because of different sensitivity of cancer cells to berberine. It can be found from the MTT results that MHCC97-L cells exhibit the highest resistance when exposed to berberine. The IC50 of berberine in HepG2 cells was approximately $100 \mu \mathrm{M}$ after $48 \mathrm{hr}$ treatment and MHCC97-L cells showed higher resistance 
to berberine, which IC50 was at dose of $250 \mu \mathrm{M}$ (Fig.1A). Addition of 3-MA reduces berberine's action on hepatocellular carcinoma cell viability (Fig.1B). Consistent result can be observed that silencing the Atg5 attenuates berberine induced hepatoma cell death (Fig.1C and 1D), indicating that autophagy may act as one of the mechanisms of anti-cancer action of berberine.

\section{Berberine induces autophagy and apoptosis in liver cancer cells}

Autophagy is a process that may function either as an approach for cell survival under certain circumstances or as a second type of programmed cell death (Type II PCD) [Hsieh et al., 2009]. In cell proceeding autophagy, cytoplasmic proteins are sequestrated into lytic components and is characterized by formation and prototion of Autophagic vacuole and acidic vacuole [Gao, et al., 2009]. MDC is a chemical probe that has been generally and widely used as a marker for autophgic avuoles because of its ability to show the accumulation of autophagic vacuoles in acidic compartments enriched in lipids [Bampton et al., 2005]. In our study, obviously increased staining intensity in cytoplasm in HepG2 and MHCC97-L cells could be observed in dose-dependent manner (Fig. 2A). Consistent results could be observed when cells treated with or without berberine were stained by acridine orange (AO), which is a specific fluorescent probe frequently used to stain lysosome [Moriyama et al., 1982]. Fig. 2B shows the accumulation of lysosome in cells treated with berberine. Moreover, addition of 3-MA suppresses the formation of autophagosome and autolysosome (Fig. 2A and 2B). The increased expression of LC3-II bands could be detected in cells treated with berberine. These results indicated the induction of autophagy in liver cancer cells exposed to berberine. 
Moreover, berberine's property on inducing autophagy was further confirmed by the accumulation of GFP-LC3 fusion protein in HepG2 cells nucleofected with a pcDNA3 plasmid encoding GFP-LC3 fusion protein (Fig. 2D). Quantification of GFP-LC3 puncta shows that berberine treatment induced dose-dependent puncta of autophagosome, and silencing the expression of Atg5 blocked the action of berberine (Fig. 2D, right). Addiction of bafilomycin A1, an autophagosome-lysosome fusion inhibitor in combination with berberine exposure results in the significant decrease of LC3-I form (Fig. 2E), indicating that berberine is able to transfer the cytoplasmic form of LC3 into autophagysome form. These results demonstrated berberine's property in inducing autophagy in hepatocellular carcinoma cells.

To assess the other type of programmed cell death, apoptosis, in HepG2 and MHCC97-L cells treated by berberine, Annexin V/PI double-staining was introduced to this study. The results showed that berberine could significantly induce early and median apoptosis after $12 \mathrm{hr}$ treatment (Fig. 3A). The induction of apoptosis by berberine was enhanced in dosedependent manner (Fig. 3B). These results suggested that berberine could induce apoptosis but not necrosis in hepatocellular carcinoma cells.

Loss of mitochondria membrane potential activates the mitochondrial cell apoptosis signal pathway in cells treated by berberine

Dose-dependent dropping fluorescent signal could be observed in both HepG2 and MHCC97-L cells treated with different concentration of berberine when compared with 
control group, indicating the loss of transmembrane potential induced by berberine in HepG2 and MHCC97-L cells (Fig.4A and 4B). Immunoblotting study presented the overexpression of Bax, cleaved caspase-3 and caspase-9 after berberine treatment (Fig.4C), indicating that berberine could induce liver cancer cell apoptosis via mitochondrial cell death pathway in dose-dependent manner (Fig.4D).

Inhibition of Bcl-2 expression and activation of Beclin-1 in the mitochondrial apoptosis and autophagy

$\mathrm{Bcl}-2$ is a member of Bcl-2 family, whose members share at least one Bcl-2 homology ( $\mathrm{BH})$ region in their structures. The Bcl-2 protein serves as an anti-apoptotic factor via stabilizing the mitochondria membrane and preventing pro-apoptotic factor releasing into cytosol [Levine et al., 2008]. Interestingly, extensive studies have found that Bcl-2 may also serve as an autophagy inhibitor via inhibiting the Beclin-1 expression in various kinds of cancer cells [Pattingre \& Levine, 2001]. Beclin-1 was initially discovered as a Bcl-2-interacting protein and a positive regulator of autophagy induction in eukaryotic cells [Sun, et al., 2009]. Beclin-1 was also identified as a tumor suppressor in various kinds of cancers [Yue et al., 2003; Qu et al., 2003; Liang et al., 1999], indicating its important role in autophagic cell death during cancer therapy. In this study, the expression of Bcl-2 was inhibited by berberine in HepG2 and MHCC97-L cells, and increasing Beclin-1 expression could be observed in cells exposed to different concentrations of berberine (Fig. 5). Moreover, the overexpression of Bax, a pro-apoptotic factor important for PT pore formation, showed an apparent mitochondrial apoptotic manner in HepG2 and MHCC97-L cells treated with berberine. 
These results suggested that berberine could serve to activate Beclin-1 and Bax via suppressing the Bcl-2 expression. The activation of Beclin-1 and Bax, as a result, could induce both apoptotic cell death (Type I PCD) and autophagic cell death (Type II PCD) in hepatocellular carcinoma cells.

Activation of P38 MAPK and inhibition of Akt signaling contribute to the mTOR inhibition by berberine and induce autophagy in hepatocellular carcinoma cells

Mammalian target of rapamycin (mTOR) is a serine/threonine protein kinase involved in many processes in cells. Cell proliferation, migration and protein synthesis were reported by mTOR signaling [Hay \& Sonenberg, 2004; Beever, et al., 2006]. The mTOR signaling was reported to negatively regulate autophagy and Inhibition of mTOR activity induces autophagy in some previous studies [Wang et al., 2009; Tang et al., 2007]. In this study, significant inhibition of mTOR activity by berberine treatment could be observed in both HepG2 and MHCC97-L cells in dose-dependent manner, indicating that mTOR suppression could contribute to the autophagy induction by berberine (Fig. 5A and 5B). Moreoever, sorts of signaling transduction have been found to regulate the activity of mTOR, including P38 MAPK, MEK/Erk and Akt [Tang, et al., 2008; Wang et al., 2009; Bommareddy et al., 2009]. In this study, Akt inhibiton was observed in dose-dependent manner (Fig. 5A and 5B), revealing that Akt could function as a regulator of mTOR and autopahgy in berberine's action. Furthermore, it is interesting to find that P38 MAPK was significantly activated by berberine in HepG2 cells but not in MHCC97-L. With the observation that mTOR signaling inhibition in MHCC97-L cells was not as significant as in HepG2 cells, this finding indicated that a 
cell-type difference in the regulation of P38 MAPK activity by berberine may affect its action on mTOR activity (Fig. 5A and 5B).

\section{Discussion and Conclusion}

With a long history of clinical use in both Chinese and Ayurvedic medicine, berberine has been conventionally used for the treatment of infectious diseases including bacterial diarrhea, intestinal parasite infections, and ocular trachoma infections regarding its prominent anti-microbial activity against bacteria, viruses, fungi, protozoans, helminths, and chlamydia [Birdsall \& Kelly, 1997]. Extensive studies also reported berberine's action on cancer in vitro and in vivo, including anti-proliferation, G2/M cell cycle arrest and apopotosis induction of HepG2, however, the underlying mechanism of berberine-induced cancer cell death is not fully revealed yet [Tang et al., 2009]. The nonsteroidal anti-inflammatory drug (NSAID)-activated gene (NAG-1) was reported as the molecular target of berberine on HepG2 [Auyeung \& Ko, 2009]. In the present study, we tried to draw a more comprehensive illustration on berberine-induced cell death including apoptosis and autophagy in cancer cells by using hepatocellular carcinoma cell models. Berbeirne induced Bax activation in HepG2 and MHCC97-L followed by the formation of PT pore and reduction of mitochondrial membrane potential, and allowed Cyto $\mathrm{C}$ to release from mitochondria to cytosol. The subsequent activation of caspase signal pathway resulted in apoptosis. Besides, berberine inhibited the expression of anti-apoptotic factor Bcl-2 but enhanced Beclin-1 expression, releasing Beclin-1 from Bcl-2/Beclin-1 complex, and eventually induced autophagy. These 
results demonstrated that berberine induced both apoptotic and autophagic cell death in liver cancer cells. The role of autophagy in cancer cell death is controversial and needs classification in particular cases. Some studies reported that autopahgy involved in chemotherapeutic agent induced cancer cell death as a pro-survival approach for cancer cell [Sy et al., 2008] since autophagy is considered as a self-defensive action when cancer cells undergo nutrient starvation, hypoxia and ionizing radiation [Ito, et al., 2005]. While in other cases, autophagy may exert self-destructive action and enhance cancer cell death [Kanzawa et al., 2003]. In the present study, 3-MA potently attenuated the cytotoxicity of berberine to liver cancer cell HepG2 and MHCC97-L (Fig.1B), indicating that both apoptosis and autophagy could contribute to cell death in this particular case. Consistent palliative action on the HepG2 cell death by blocking the autophagosome formation using siRNA against Atg5 gene could be observed (Fig.1C and 1D). Since 3-MA was also considered as an apoptosis inhibitor besides its inhibition on autophagy, the contribution of autophagic cell death versus apoptosis in berberine's action was calculated by comparing the inhibition rate of 3-MA and Atg5 siRNA on the cell death. Up to $30 \%$ of cell death was found to be contributed by autophagy induced by berberine in HepG2 cells at $250 \mu \mathrm{M}$ (Fig.1C), and apoptosis contributed the major action of berberine on cell death at $250 \mu \mathrm{M}$ (Fig.1B).

It was noted that berberine used in this study was a relatively high dose. In some cases, the IC50 of berberine was lower than $4 \mu \mathrm{g} / \mathrm{mL}$, which is below the safety limit established by National Cancer Institute [Leta`siová et al., 2006]. The IC50 of berberine in this study seems rather high and the reason needs to be further explored in future. However, berberine is a 
natural product which has been widely used for many years. As an anti-microbial agent, it has been used to cure microbial-related gastric diseases. The dose varies and can be very high, even up to 1 gram per day [China Pharmacopeia, 2005 edition]. Our other studies also showed that berberine revealed very low cytotoxicity on rat hepatocyte (data not shown) and has liver protective effect in liver damage animal model [Ye et al., 2009]. These data suggested berberine's low toxicity and indicated that berberine can be used at high dose. Actually, a phase I dose escalation study of Huanglian (Chinese medicines which main active compound is berberine) in patients with advanced solid tumours has been conduced at Memorial Sloan-Kettering Cancer Center (http://www.cancer.gov/clinicaltrials/MSKCC-00061) due to the potential of berberine and Huanglian in vitro results and Chinese Medicine practice in the treatment of cancers [Tang et al., 2009]. New molecular targets, dosage of berberine and cell lines used in this study will provide useful information for further study.

Several signal pathways are involved in the regulation of autophagy in cancer cells, including Beclin-1, PI3K/Akt/mTOR, death associated protein kinase (DAPK) and Bcl-2 pathways [Kondo et al., 2005]. Exogenous expression of Beclin-1 in MCF-7 cells does not endogenously generate Belcin-1 initiated autophagy and results in cell death [Liang et al., 1999]. Besides, some studies reported that Bcl-2 can negatively regulate the Beclin-1 capacity to induce autophagy by binding to its BH3 domain [Ciechomska et al., 2009]. This study revealed that berberine may activate Beclin-1 from Bcl-2/Beclin-1 complexes via inhibiting the expression of $\mathrm{Bcl}-2$ (Fig.5A and 5B). Another important mechanism of autophagy is the mTOR signaling pathway, which is constantly activated in different kinds of 
cancers [Vivanco \& Sawyers, 2002]. It was demonstrated that TOR kinases is an upstream negative regulator for all autophagy-associated genes in yeasts [Wang \& Klionsky, 2003]. Using rapamycin to inhibit this signaling pathway could induce autophagy and suppress the proliferation of cancer cells [Takeuchi et al., 2005], indicating that inhibitor on this pathway may contribute to cancer therapy. Since mTOR inhibition in this study has been observed, some of the up-streamed pathway of mTOR, including Erk1/2, P38 MAPK and Akt were examined. These results found that berberine did not affect Erk1/2 signaling (Data not shown), but activated P38 MAPK and inhibited the Akt activity (Fig.5A and 5B). It was suggested that the inhibition of berberine on mTOR activity is induced by combination signal of p38 MAPK activation and Akt inhibition. In HepG2 cells, significant p38 MAPK activation accelerated the mTOR inhibition by berberine, while in MHCC97-L cells, since p38 MAPK did not sensitively respond to berberine, the mTOR inhibition was induced solely by berberine's suppression on Akt activity (Fig.5A and 5B). Possible mechanism of berberine-induced autophagy in cancer cells is shown in Fig.6.

The relationship between the loss of mitochondria membrane potential and cell apoptosis has been extensively studied. Some literature considered that the collapsing of mitochondrial inner membrane potential indicates the opening of a large conductance channel, mitochondrial permeability transition pore (PT pore), and allows pro-apoptotic signals like Cyto C and caspase-activating proteins to release into cytosol [Green \& Reed, 1982]. Involvement of Bax can be observed during the formation of PT pore [Crompton, 2000]. However, recent reports showed that Cyto $\mathrm{C}$ and other pro-apoptotic release are Bax-dependent but PT pore 
formation-independent. The release of Cyto $\mathrm{C}$ is actually initiated by the rupture of outer mitochondrial membranes (OMM) by Bax activation [Knudson \& Brown, 2008] and then gets started of apoptosis process in cells. Thus the release of Cyto $\mathrm{C}$ and activation of Bax can be considered as a mark of mitochondrial apoptosis. However, the regulation and function of PT pore formation on mitochondria are in intensive debate. What is clear is that the PT pore formation is characterized by the loss of MMP, and that it plays a key role in deciding cell life or death [Zorov, et al., 2008]. Bax was also reported to be involved in the formation of PT pore [Brenner, et al. 2000], but some also reported a Bax-independent induction of PT pore formation [Mullauer, Kessler \& Medema, 2009]. In this study, Bax activation and Cyto C release were observed, indicating a possible mitochondrial apoptosis in berberine treated hepatic cancer cells. A sudden loss of MMP, along with significant cell death in both HepG2 and MHCC97-L cells treated with berberine was also observed. The exact function and mechanism of total abrupt change of mitochondrial induced by berberine need further investigation.

In this study, berberine's potential in apoptotic and autophagic cell death was systematically examined though apoptosis induced by berberine and underlying mechanism have been previously studied. We observed that apoptotic and autophagic cell death were simultaneously induced by berberine in hepatocellular carcinoma cells and evidenced by changed biochemical markers in molecular targets and cell signal pathways. Based on our result, we found that the total cell death is $20 \%-80 \%$ on berberine 100-500 $\mu \mathrm{M}$ (Fig.1B, 3-MA inhibits both apoptotic and autophagic cell 
death), while autophagic cell death may contribute only 10-25\% (Fig.1C and D, Atg5 siRNA inhibits only autophagic cell death). These results demonstrated that berberine has potential to induce both apoptotic and autophagic cell death, in which apoptosis is the major type of cell death. However, it may be noted that the cell death inhibitor (3-MA) could not fully rescue berberine-induced cell death. It is still unclear if autophagic cell death induction of berberine in small proportion is able to play significant role in treatment of cancer, but in the following mentioned specific cases, combination of berberine with radiotherapy or chemotherapy presented synergistic action on cancer cell autophagic and apoptotic cell death, in which berberine's potential in induction of cell death may be enlarged. 5 and $10 \mu \mathrm{M}$ concentrations of berberine combined with irradiation significantly strengthened the radio-sensitivity on A549 cells was observed, which molecular basis involved in the induction of autophagic cell death as well as cell-cycle G2/M arrest [Peng et al., 2008]. The synergistic anticancer effect using both $\mathrm{As}_{2} \mathrm{O}_{3}$ and berberine was also found in human neuroblastoma SH-SY5Y cells and the mechanism was based on the mitochondria/caspase-3 dependent signaling pathway [Kim et al., 2007]. At least, we got a whole picture of apoptotic and autophagic cell death induced by berberine in hepatocellular carcinoma cells in this study and as mentioned above, further investigations are required to fully characterize the concomitant mediators and determinant switches of cell death induced by berberine or combination with other therapies in cancer cell models and animal models. 
In conclusion, we presented here a novel combined mechanism involved in berberine induced cancer cell death, among which apoptosis was the major cell death and autophagic cell death was concurrent. Berberine may activate mitochondrial apoptosis in hepatocellular carcinoma cells via increasing Bax expression, PT pore formation and Cyto C released to cytosol, and subsequently activating caspase- 3 and caspase- 9 signal pathway. Berberine may also induce autophagic cell death via activating Beclin-1 and inhibiting mTOR signaling pathway. We provided a whole picture for cell death induced by berberine in hepatocellular carcinoma cells and we report for the first time the mechanism of berberine-induced autophagic cell death. As a therapeutic agent in the emerging list of alternative cancer therapy, our results shed lights on berberine's potential anticancer with novel mechanism for live cancer.

\section{Conflict of interest}

The authors have declared no conflict of interest.

\section{Acknowledgement}

The study was financially supported by grants from the research council of the University of Hong Kong (Project Codes: 200811159197 and 200907176140), The Research Grants Council (RGC) of Hong Kong SAR of China (Project Code: 764708M), Pong Ding Yueng Endowment Fund for Education \& Research in Chinese-Western Medicine (Project Code: 20005274) and Hong Kong Government-Matching Grant Scheme (4th Phase, Project Code: 20740314). The pcDNA3 plasmid encoding human LC3 was kindly gifted by Professor Tamotsu Yoshimori, Osaka Univeristy, Japan. The cell line MHCC97-L was a kind gift from 
Liver Cancer Institute, Fudan University, Shanghai, China. The authors are grateful to the support of Professors Yung-Chi Cheng and Allan SY Lau. The authors would like to express thanks to Dr. Ka-Yu Siu, Ms Cindy Lee, Mr. Keith Wong, and Mr. Freddy Tsang for their technical support. 


\section{Figure legend}

\section{Figure 1. Cytotocixity of berberine in different cancer cells}

A. shows cytotocixity of berberine in HepG2, MHCC97-L, HONE1, HK1 and Hela after 48 hr treatment. B. shows the viability of HepG2 and MHCC97-L cells after treatment with berberine plus or minus 3-MA $(10 \mathrm{mM})$. Residual cell viability following the treatment of berberine was significantly decreased in dose-dependent manner. Residual cell viability following the treatment of berberine plus $10 \mathrm{mM}$ 3-MA was significant increased. C. shows berberine's cytotoxicity can be attenuated by introducing a siRNA against ATG5 into HepG2 cells. D. Expression of Atg5 in cells transfected with control or Atg5 siRNA by Western bloting (left) and their relative expression by quantitative analysis (right) were shown. All experiments were conducted in triplicates and the results were analyzed for statistical significance $(* \mathrm{p}<0.01$ when compared with counterpart control; \# $\mathrm{p}<0.01$ when compared with counterpart berberine-treated only cells).

\section{Figure 2. Berberine induces autophagy in hepatocellular carcinoma cells}

A. shows autophagosome formation after $6 \mathrm{hr}$ treatment of berberine and berberine plus 3-MA using MDC staining. Microscopic photos were taken at 630×magnification (upper panel) and percentage of cells with positive staining was calculated (lower panel). B. shows the lysosome accumulation after $6 \mathrm{hr}$ treatment of berberien and berberine plus 3-MA using AOs staining. Microscopic photos were taken at $630 \times$ magnification (upper panel) and percentage of cells with positive staining was calculated (lower panel). C. shows immunoblot 
analysis of LC3-I (18 kDa) and LC3-II (16 kDa). Fifteen micrograms of cell lysates from HepG2 (left) or MHCC97-L (right) were subjected to Western blot analysis using LC3B antibody (upper panel) and the relative expression of LC3-II protein was calculated (lower panel). D. shows that berberine could induce GFP-LC3 fusion protein accumulation in HepG2 cells nucleofected with pcDNA3 plasmid encoding GFP-LC3 at 630×magnification (left) and percentage of cells with autophagy puncta (right). Relative expression of Atg5 in cells transfected with control or Atg5 siRNA was shown in Fig. 1D. $\mathbf{E}$ shows the expression of LC3-I and LC-II in HepG2 cells exposed to berberine $(200 \mu \mathrm{M})$ or vehicle in the presence of bafilomycin A1 (32 nM) $(* \mathrm{p}<0.05, * * \mathrm{p}<0.01$ when compared with counterpart control; \# $\mathrm{p}<0.05, \# \# \mathrm{p}<0.01$ when compared with counterpart berberine-treated only cells).

\section{Figure 3. Berberine induces apoptosis in hepatocellular carcinoma cells}

A. HepG2 and MHCC97-L cells were stained with Annexin V $(0.5 \mu \mathrm{g} / \mathrm{mL})$ and PI $(2 \mu \mathrm{g} / \mathrm{mL})$ after $12 \mathrm{hr}$ treatment of berberine for FACS analysis. B. quantitative data shows berberine induces HepG2 (left) and MHCC97-L (right) cells apoptosis in dose-dependent manner. All experiments were conducted in triplicates and the results were analyzed for statistical significance $(* \mathrm{p}<0.05, * * \mathrm{p}<0.01, * * * \mathrm{p}<0.001, * * * * \mathrm{p}<0.0001$ when compared with counterpart control)

Figure 4 Berberine induced mitochondrial apoptosis in hepatocellular carcinoma cells

A. shows the decrease of mitochondrial membrane potential after $12 \mathrm{hr}$ treatment of berberine or vehicle in HepG2 and MHCC97-L cells. Microscopic photos were taken at 630x 
Figure 5. Autophagy related signal transduction in hepatocellular carcinoma cells with or without treatment of berberine

A. HepG2 and MHCC97-L cells were treated with indicating dosages of berberine for $6 \mathrm{hr}$, and fifteen micrograms of cell lysates from HepG2 cells (left) and MHCC97-L cells (right) were subjected to western blot analysis using related antibodies. B. shows quantitative analysis for relative protein expression in A. All experiments were conducted in triplicates. (* $\mathrm{p}<0.05, * * \mathrm{p}<0.01$ when compared with counterpart control).

Figure 6. Possible mechanism involved in berberine-regualting autophagy in liver cancer cells

The schematic signaling patterns display that Bcl-2/Beclin-1 complexes and PI3K/Akt/mTOR signaling pathway are modulated by berberine in regualting autophagy in liver cancer cells. Our study revealed that berberine may activate Beclin-1 from Bcl-2/Beclin-1 complexes via inhibiting the expression of Bcl-2 and on the other hand, inhibition of mTOR by berberine responsible for the inhibition of Akt and activation of P38 MAPK may initiate autophagy. 
Berberine makes both signaling pathways work together to enhance authophagy in hepatoma cells. 


\section{Reference}

Auyeung KK, Ko JK. 2009. Coptis chinensis inhibits hepatocellular carcinoma cell growth through nonsteroidal anti-inflammatory drug-activated gene activation. Int J Mol Med. 24: $571-7$.

Bampton ET, Goemans CG, Niranjan D, Mizushima N, Tolkovsky AM. 2005. The dynamics of autophagy visualized in live cells: from autophagosome formation to fusion with endo/lysosomes. Autophagy. 1:23-36.

Beevers CS, Li F, Liu L, Huang S. 2006. Curcumin inhibits the mammalian target of rapamycin-mediated signaling pathways in cancer cells. Int J Cancer. 119: 757-64.

Birdsall TC, Kelly GS. 1997. Berberine: Therapeutic potential of an alkaloid found in several medicinal plants. Altern Med Rev 2:94-103.

Bommareddy A, Hahm ER, Xiao D, Powolny AA, Fisher AL, Jiang Y, Singh SV.. 2009. Atg5 regulates phenethyl isothiocyanate-induced autophagic and apoptotic cell death in human prostate cancer cells. Cancer Res 69:3704-12.

Brenner C, Cadiou H, Vieira HL, Zamzami N, Marzo I, Xie Z, Leber B, Andrews D, Duclohier H, Reed JC, Kroemer G.. 2000. Bcl-2 and Bax regulate the channel activity of the 
mitochondrial adenine nucleotide translocator. Oncogene. 19: 329-36.

Budhu A, Jia HL, Forgues M, Liu CG, Goldstein D, Lam A, Zanetti KA, Ye QH, Qin LX, Croce CM, Tang ZY, Wang XW. 2008. Identification of Metastasis-Related MicroRNAs in Hepatocellular Carcinoma. Hepatology 47: 897-907.

Crompton M. 2000. Mitochondrial intermembrane junctional complexes and their role in cell death. J Physiol 529:11-21.

Ciechomska IA, Goemans GC, Skepper JN, Tolkovsky AM. 2009. Bcl-2 complexed with Beclin-1 maintains full anti-apoptotic function. Oncogene 28:2128-41.

Cheng Y, Qiu F, Ikejima T. 2009. Molecular mechanisms of oridonin-induced apoptosis and autophagy in murine fibrosarcoma L929 cells. Autophagy 5:430-1.

Green DR, Reed JC. 1998. Mitochondria and apoptosis. Science 281:1309-12.

Galluzz L, Vicencio JM, Kepp O, Tasdemir E, Maiuri MC, Kroemer G. 2008. To die or not to die, that is the autophagic question. Curr Mol Med 8:78-91.

Gao M, Yeh PY, Lu YS, Hsu CH, Chen KF, Lee WC, Feng WC, Chen CS, Kuo ML, Cheng AL.. 2008. OSU-03012, a novel celecoxib derivative, induces reactive oxygen species-related 
autophagy in hepatocellular carcinoma. Cancer Res 68:9348-57.

Hsieh YC, Athar M, Chaudry IH. 2009. When apoptosis meets autophagy: deciding cell fate after trauma and sepsis. Trends Mol Med 15:129-38.

Hay N, Sonenberg N. 2004. Upstream and downstream of mTOR. Genes Dev. 2004 18: $1926-45$.

Ito H, Daido S, Kanzawa T, Kondo S, Kondo Y. 2005. Radiation-induced autophagy is associated with LC3 and its inhibition sensitizes malignant glioma cells. Int J Oncol 26:1401-10.

Kanzawa T, Kondo Y, Ito H, Kondo S, Germano I. 2003. Induction of autophagic cell death in malignant glioma cells by arsenic trioxide. Cancer Res 63:2103-8.

Kim DW, Ahan SH, Kim TY. 2007. Enhancement of Arsenic Trioxide (As(2)O(3))- Mediated Apoptosis Using Berberine in Human Neuroblastoma SH-SY5Y Cells. J Korean Neurosurg Soc 42:392-9.

Kim RH, Coates JM, Bowles TL, McNerney GP, Sutcliffe J, Jung JU, Gandour-Edwards R, Chuang FY, Bold RJ, Kung HJ.. 2009. Arginine deiminase as a novel therapy for prostate cancer induces autophagy and caspase-independent apoptosis. Cancer Res 69:700-8. 
Knudson CM, Brown NM. 2008. Mitochondria potential, bax "activation," and programmed cell death. Methods Mol Biol. 414: 95-108.

Kondo Y, Kanzawa T, Sawaya R, Kondo S. 2005. The role of autophagy in cancer development and response to therapy. Nat Rev Cancer 5:726-34.

Kroemer G, Galluzzi L, Vandenabeele P, Abrams J, Alnemri ES, Baehrecke EH, Blagosklonny MV, El-Deiry WS, Golstein P, Green DR, Hengartner M, Knight RA, Kumar S, Lipton SA, Malorni W, Nuñez G, Peter ME, Tschopp J, Yuan J, Piacentini M, Zhivotovsky B, Melino G; Nomenclature Committee on Cell Death 2009.. 2009. Classification of cell death: recommendations of the Nomenclature Committee on Cell Death 2009. Cell Death Differ $16: 3-11$.

Lee TK, Man K, Ho JW, Wang XH, Poon RT, Xu Y, Ng KT, Chu AC, Sun CK, Ng IO, Sun HC, Tang ZY, Xu R, Fan ST.. 2005. FTY720: a promising agent for treatment of metastatic hepatocellular carcinoma. Clin Cancer Res 11:8458-66.

Letasiová S, Jantová S, Cipák L, Múcková M. 2006. Berberine-antiproliferative activity in vitro and induction of apoptosis/necrosis of the U937 and B16 cells. Cancer Lett 239:254-62.

Levine B, Sinha S, Kroemer G. 2008. Bcl-2 family members: dual regulators of apoptosis and 
autophagy. Autophagy 4: 600-6.

Liang XH, Jackson S, Seaman M, Brown K, Kempkes B, Hibshoosh H, Levine B.. 1999. Induction of autophagy and inhibition of tumorigenesis by beclin 1 . Nature 402:672-6.

Lin S, Tsai SC, Lee CC, Wang BW, Liou JY, Shyu KG.. 2004. Berberine inhibits HIF-1alpha expression via enhanced proteolysis. Mol Pharmacol 66: 612-9.

Munafó DB, Colombo MI. 2001. A novel assay to study autophagy: regulation of autophagosome vacuole size by amino acid deprivation. J Cell Sci 114: 3619-29.

Mullauer FB, Kessler JH, Medema JP. 2009. Betulinic acid induces cytochrome c release and apoptosis in a Bax/Bak-independent, permeability transition pore dependent fashion. Apoptosis. 14:191-202.

Moriyama Y, Takano T, Ohkuma S. 1982. Acridine Orange as a Fluorescent Probe for Lysosomal Proton Pump. J Biochem 92:1333-6.

Pereira GC, Branco AF, Matos JA, Pereira SL, Parke D, Perkins EL, Serafim TL, Sardão VA, Santos MS, Moreno AJ, Holy J, Oliveira PJ.. 2007. Mitochondrially-targetted effects of berberine onK1735-M2mousemelanoma cells comparison with direct effects on isolated mitochondrial Fractions. J Pharmacol Exp Ther 323: 636-49. 
Peng PL, Kuo WH, Tseng HC, Chou FP. 2008. Synergistic tumor-killing effect of radiation and berberine combined treatment in lung cancer: the contribution of autophagic cell death. Int J Radiat Oncol Biol Phys 70:529-42.

Pattingre S, Levine B. 2006. Bcl-2 Inhibition of Autophagy: A New Route to Cancer? Cancer Res 66:2885-8.

Pandey MK, Sung B, Kunnumakkara AB, Sethi G, Chaturvedi MM, Aggarwal BB. 2008. Berberine modifies cysteine 179 of IkappaBalpha kinase, suppresses nuclear factor-kappaB-regulated antiapoptotic gene products, and potentiates apoptosis. Cancer Res 68(13):5370-9.

Qu X, Yu J, Bhagat G, Furuya N, Hibshoosh H, Troxel A, Rosen J, Eskelinen EL, Mizushima N, Ohsumi Y, Cattoretti G, Levine B.. 2003. Promotion of tumorigenesis by heterozygous disruption of the beclin 1 autophagy gene. J Clin Invest 112:1809-20.

Sun Q, Fan W, Zhong Q. 2009. Regulation of Beclin 1 in autophagy. Autophagy 2009; 5:713-6.

Shen S, Kepp O, Martins I, Vitale I, Souquère S, Castedo M, Pierron G, Kroemer G.. 2010. Defective autophagy associated with LC3 puncta in epothilone-resistant cancer cells. Cell 
Cycle 9:377-83.

Serafim TL, Oliveira PJ, Sardao VA, Perkins E, Parke D, Holy J.. 2008. Different concentrations of berberine result in distinctcellular localization patterns and cell cycle effects in a melanoma cell line. Cancer Chemother Pharmacol 61:1007-18.

Sy LK, Yan SC, Lok CN, Man RY, Che CM. 2008. Timosaponin A-III induces autophagy preceding mitochondria-mediated apoptosis in HeLa cancer cells. Cancer Res 68:10229-37.

Takeuchi H, Kondo Y, Fujiwara K, Kanzawa T, Aoki H, Mills GB, Kondo S.. 2005. Synergistic augmentation of rapamycin-induced autophagy in malignant glioma cells by phosphatidylinositol 3-kinase/protein kinase B inhibitors. Cancer Res 65:3336-46.

Tang J, Feng Y, Tsao S, Wang N, Curtain R, Wang Y. Berberine and Coptidis Rhizoma as novel antineoplastic agents: a review of traditional use and biomedical investigations. 2009. J Ethnopharmacol 126:5-17..

Tsang CM, Lau EP, Di K, Cheung PY, Hau PM, Ching YP, Wong YC, Cheung AL, Wan TS, Tong Y, Tsao SW, Feng Y.. 2009. Berberine inhibits Rho GTPases and cell migration at low doses but induces G2 arrest and apoptosis at high doses in human cancer cells. Int J Mol Med. 24(1):131-8. 
Tang G, Yue Z, Talloczy Z, Hagemann T, Cho W, Messing A, Sulzer DL, Goldman JE... 2008. Autophagy induced by Alexander disease-mutant GFAP accumulation is regulated by p38/MAPK and mTOR signaling pathways. Hum Mol Genet. 17: 1540-55.

Vermes I, Haanen C, Steffens-Nakken H, Reutelingsperger C. 1995. A novel assay for apoptosis. Flow cytometric detection of phosphatidylserine expression on early apoptotic cells using fluorescein labelled Annexin V. J Immunol Methods 184: 39-51.

Vivanco I, Sawyers CL. 2002. The phosphatidylinositol 3-Kinase AKT pathway in human cancer. Nat Rev Cancer 2:489-501.

Wang CW, Klionsky DJ. 2003. The molecular mechanism of autophagy. Mol Med 9:65-76.

Wang J, Whiteman MW, Lian H, Wang G, Singh A, Huang D, Denmark T.. 2009. A non-canonical MEK/ERK signaling pathway regulates autophagy via regulating Beclin 1. J Biol Chem. 284: 21412-24.

Yang C, Kaushal V, Shah SV, Kaushal GP. 2008. Autophagy is associated with apoptosis in cisplatin injury to renal tubular epithelial cells. Am J Physiol Renal Physiol 294: F777-87.

Ye X, Feng Y, Tong Y, Ng KM, Tsao S, Lau GK, Sze C, Zhang Y, Tang J, Shen J, Kobayashi S. 2009. Hepatoprotective effects of Coptidis rhizoma aqueous extract on carbon 
tetrachloride-induced acute liver hepatotoxicity in rats. J Ethnopharmacol 124:130-6.

Zorov DB, Juhaszova M, Yaniv Y, Nuss HB, Wang S, Sollott SJ. 2009. Regulation and pharmacology of the mitochondrial permeability transition pore. Cardiovasc Res. $83: 213-25$. 

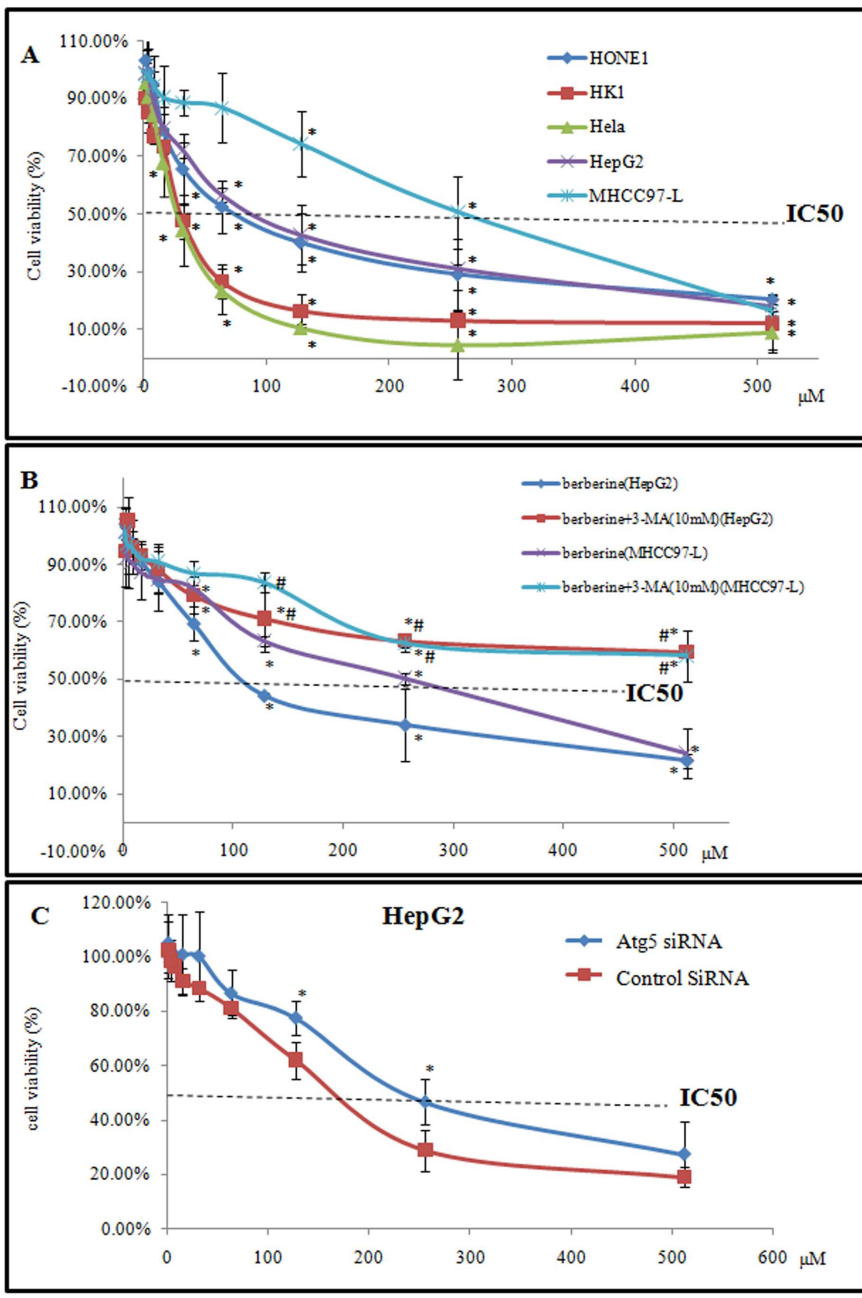

D

Control siRNA Atg 5 siRNA
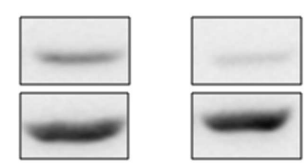

$55 \mathrm{kDa}$
ATG5
$47 \mathrm{kDa}$
$\beta$-actin

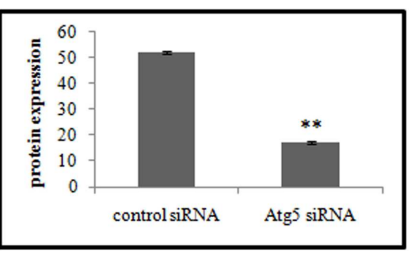

Figure 1. Cytotocixity of berberine in different cancer cells

A. shows cytotocixity of berberine in HepG2, MHCC97-L, HONE1, HK1 and Hela after $48 \mathrm{hr}$ treatment. B. shows the viability of HepG2 and MHCC97-L cells after treatment with berberine plus or minus 3-MA (10 mM). Residual cell viability following the treatment of berberine was significantly decreased in dose-dependent manner. Residual cell viability following the treatment of berberine plus $10 \mathrm{mM}$ 3-MA was significant increased. C. shows berberine's cytotoxicity can be attenuated by introducing a siRNA against ATG5 into HepG2 cells. D. Expression of Atg5 in cells transfected with control or Atg 5 siRNA by Western bloting (left) and their relative expression by quantitative analysis (right) were shown. All experiments were conducted in triplicates and the results were analyzed for statistical significance $(* p<0.01$ when compared with counterpart control; \# $p<0.01$ when compared with counterpart berberine-treated only cells). $160 \times 277 \mathrm{~mm}(300 \times 300 \mathrm{DPI})$ 

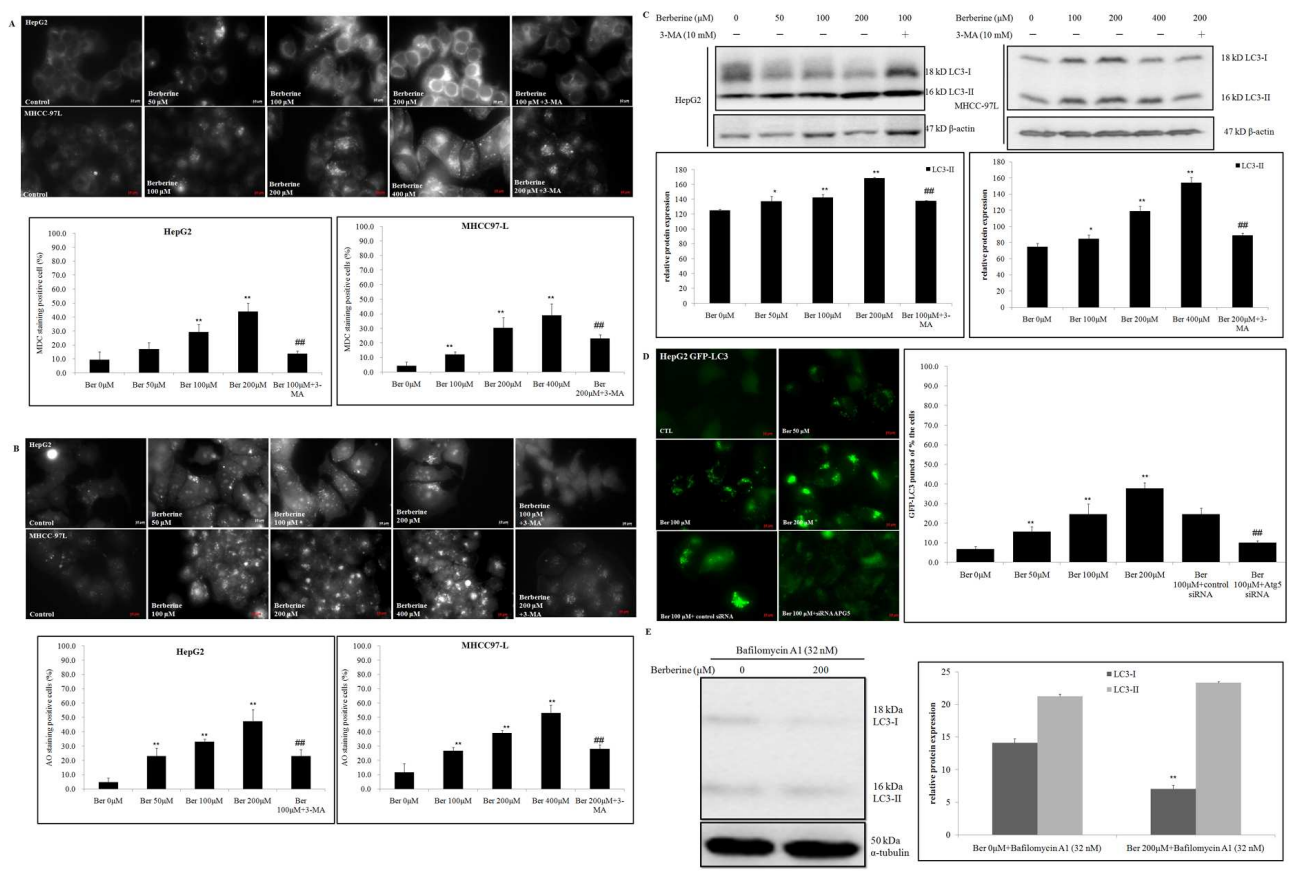

Figure 2. Berberine induces autophagy in hepatocellular carcinoma cells A. shows autophagosome formation after $6 \mathrm{hr}$ treatment of berberine and berberine plus 3-MA using MDC staining. Microscopic photos were taken at $630 \times$ magnification (upper panel) and percentage of cells with positive staining was calculated (lower panel). B. shows the lysosome accumulation after $6 \mathrm{hr}$ treatment of berberien and berberine plus 3-MA using AOs staining. Microscopic photos were

taken at $630 \times$ magnification (upper panel) and percentage of cells with positive staining was calculated (lower panel). C. shows immunoblot analysis of LC3-I (18 kDa) and LC3-II (16 kDa). Fifteen micrograms of cell lysates from HepG2 (left) or MHCC97-L (right) were subjected to Western blot analysis using LC3B antibody (upper panel) and the relative expression of LC3-II protein was calculated (lower panel). D. shows that berberine could induce GFP-LC3 fusion protein accumulation in HepG2 cells nucleofected with pcDNA3 plasmid encoding GFP-LC3 at 630×magnification (left) and percentage of cells with autophagy puncta (right). Relative expression of Atg5 in cells transfected

with control or Atg5 siRNA was shown in Fig. 1D. E shows the expression of LC3-I and LC-II in HepG2 cells exposed to berberine $(200 \mu \mathrm{M})$ or vehicle in the presence of bafilomycin A1 (32 nM) (* $\mathrm{p}<0.05,{ }^{*} \mathrm{p}<0.01$ when compared with counterpart control; \# $\mathrm{p}<0.05, \# \# \mathrm{p}<0.01$ when compared with counterpart berberine-treated only cells). $160 \times 106 \mathrm{~mm}(300 \times 300 \mathrm{DPI})$ 

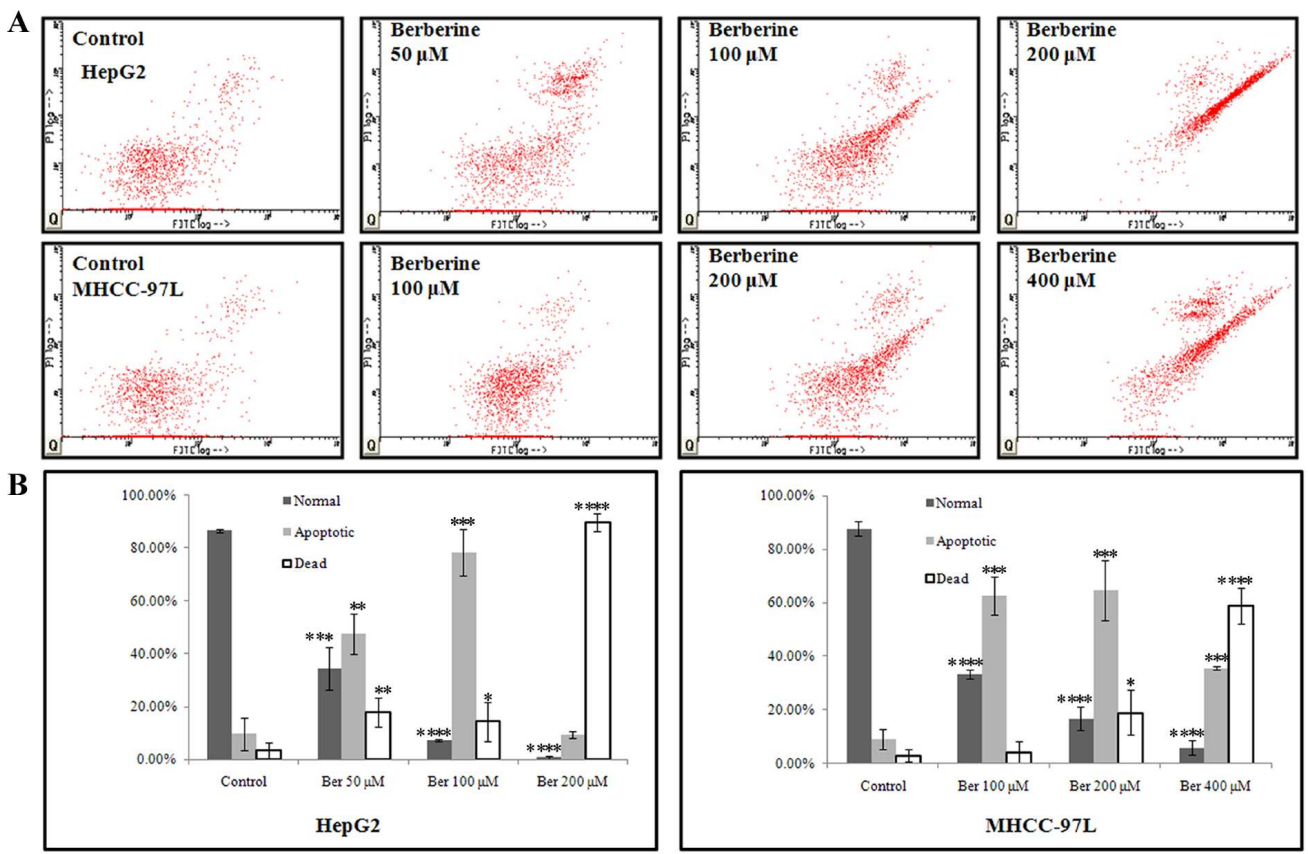

Figure 3. Berberine induces apoptosis in hepatocellular carcinoma cells A. HepG2 and MHCC97-L cells were stained with Annexin V $(0.5 \mu \mathrm{g} / \mathrm{mL})$ and PI $(2 \mu \mathrm{g} / \mathrm{mL})$ after $12 \mathrm{hr}$ treatment of berberine for FACS analysis. B. quantitative data shows berberine induces HepG2 (left) and MHCC97-L (right) cells apoptosis in dose-dependent manner. All experiments were conducted in triplicates and the results were analyzed for statistical significance $(* p<0.05, * * p<0.01$, $* * * \mathrm{p}<0.001, * * * * \mathrm{p}<0.0001$ when compared with counterpart control) $160 \times 103 \mathrm{~mm}(300 \times 300 \mathrm{DPI})$ 
A
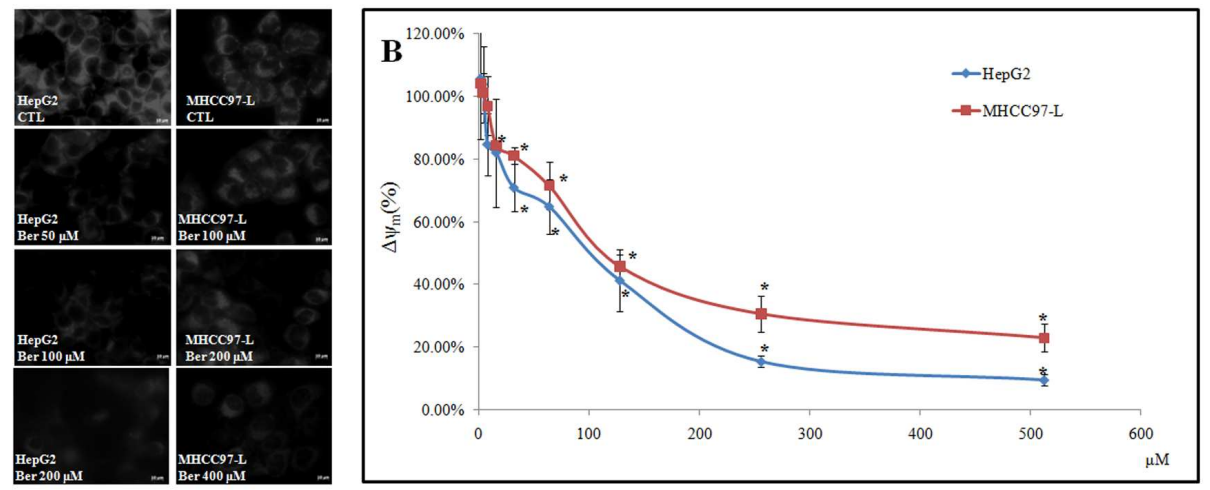

C

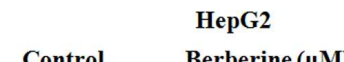

Berberine $(\mu \mathrm{M})$

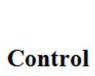

MHCC-97L
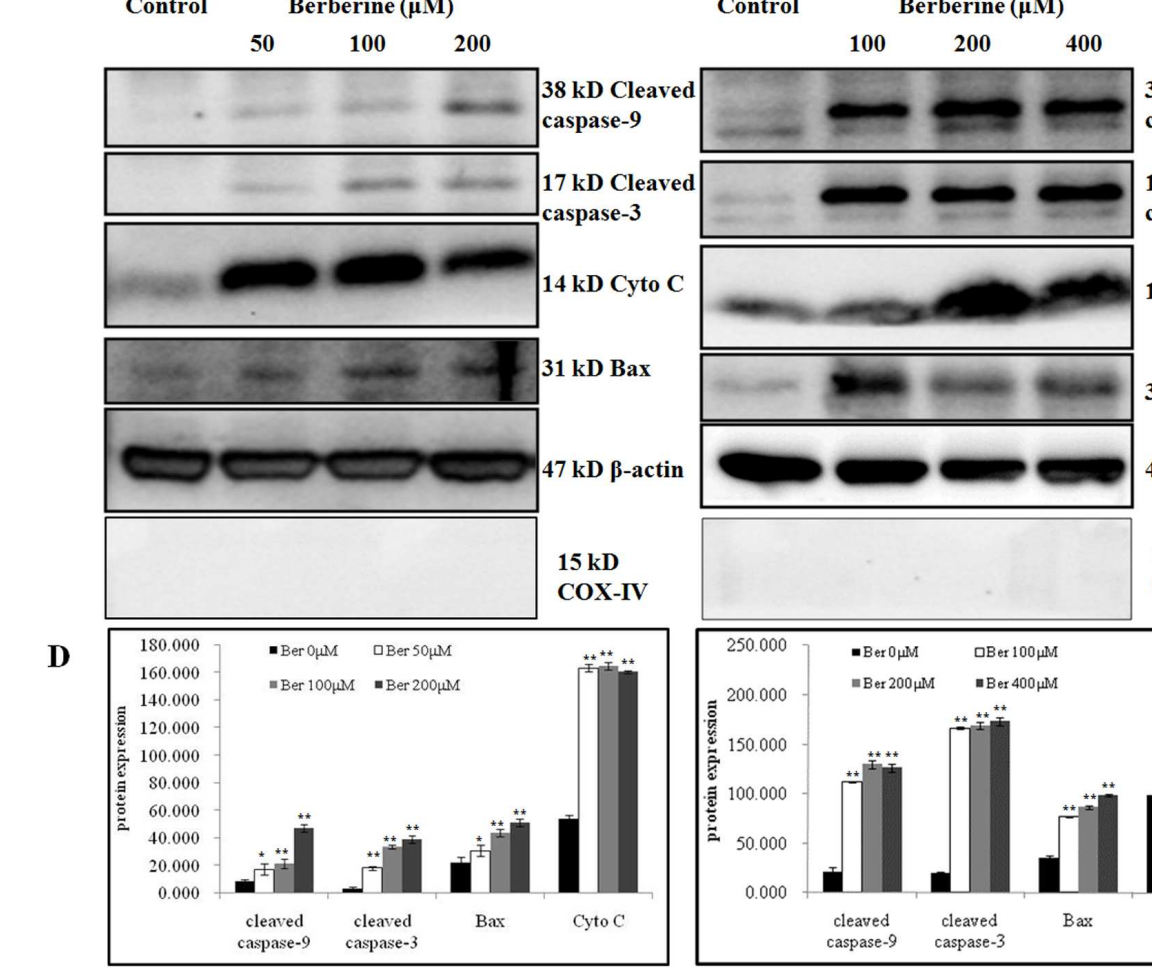

$38 \mathrm{kD}$ Cleaved caspase-9

$17 \mathrm{kD}$ Cleaved caspase-3

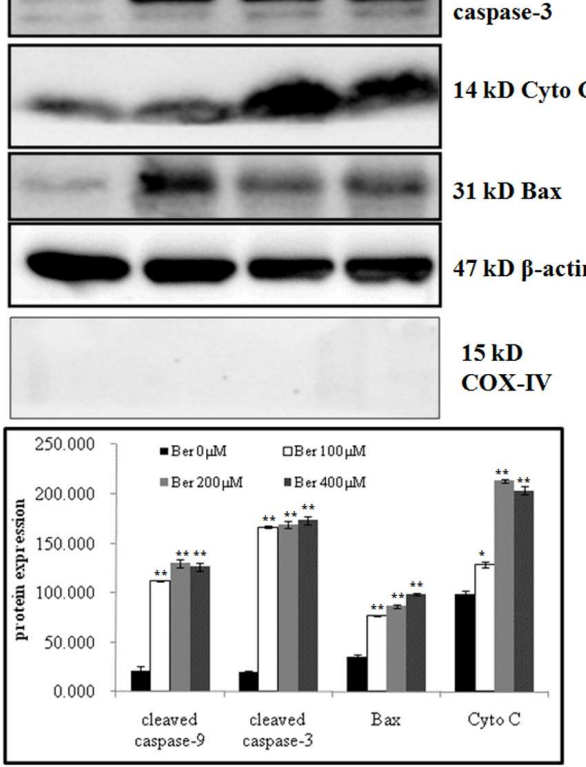

Figure 4 Berberine induced mitochondrial apoptosis in hepatocellular carcinoma cells A. shows the decrease of mitochondrial membrane potential after $12 \mathrm{hr}$ treatment of berberine or vehicle in HepG2 and MHCC97-L cells. Microscopic photos were taken at $630 \times$ magnification. B. shows the quantitative analysis of fluorescent signal drop with increase of berberine's concentration (stained by Rh-123) in HepG2 and MHCC97-L cells. C. shows the mitochondrial apoptosis pathway related protein expression in HepG2 and MHCC97-L cells with treatment of berberine or vehicle by

Western blot analysis. D. shows quantitative analysis for relative protein expression in C. All experiments were conducted in triplicates. $(* p<0.05, * * p<0.01$ when compared with counterpart control). $160 \times 187 \mathrm{~mm}(300 \times 300 \mathrm{DPI})$ 

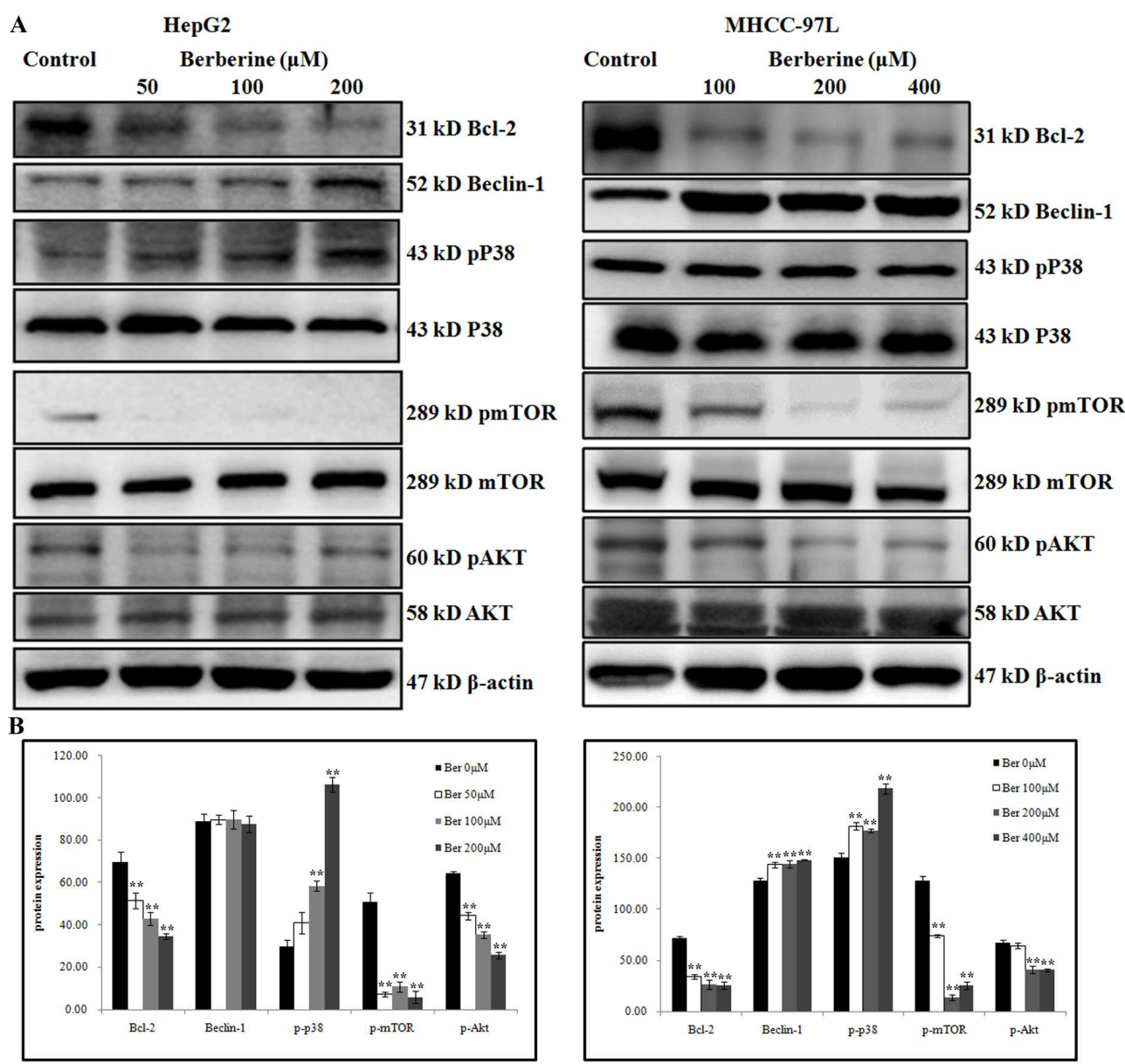

Figure 5. Autophagy related signal transduction in hepatocellular carcinoma cells with or without treatment of berberine

A. HepG2 and MHCC97-L cells were treated with indicating dosages of berberine for $6 \mathrm{hr}$, and fifteen micrograms of cell lysates from HepG2 cells (left) and MHCC97-L cells (right) were subjected to western blot analysis using related antibodies. B. shows quantitative analysis for relative protein expression in A. All experiments were conducted in triplicates. ( $*<<0.05, * * p<0.01$ when compared with counterpart control). $160 \times 148 \mathrm{~mm}(300 \times 300 \mathrm{DPI})$ 
Figure 6. Possible mechanism involved in berberine-regualting autophagy in liver cancer cells The schematic signaling patterns display that Bcl-2/Beclin-1 complexes and PI3K/Akt/mTOR signaling pathway are modulated by berberine in regualting autophagy in liver cancer cells. Our study revealed that berberine may activate Beclin-1 from Bcl-2/Beclin-1 complexes via inhibiting the expression of $\mathrm{BCl}-2$ and on the other hand, inhibition of mTOR by berberine responsible for the inhibition of Akt and activation of P38 MAPK may initiate autophagy. Berberine makes both signaling pathways work together to enhance authophagy in hepatoma cells. $160 \times 181 \mathrm{~mm}(400 \times 400 \mathrm{DPI})$ 